\title{
Surgical treatment of isolated and syndromic craniosynostosis. Results and complications in 283 consecutive cases
}

\author{
J. Esparza*; J. Hinojosa*; I. García-Recuero**; A. Romance**; B. Pascual* y A. Martínez de Aragón*** \\ Unidad de Cirugía Craneofacial (Servicios de Neurocirugía Pediátrica*, Maxilofacial** y Neurorradiología***). Hospital Infantil 12 de \\ Octubre. Madrid.
}

\section{Summary}

Objective. To review the results and complications of the surgical treatment of craniosynostosis in 283 consecutive patients treated between 1999 and 2007.

Patients and methods. Our series consisted of 330 procedures performed in 283 patients diagnosed with scaphocephaly $(n=155)$, trigonocephaly $(n=50)$, anterior plagiocephaly $(n=28)$, occipital plagiocephaly $(n=1)$, non-syndromic multi-suture synostosis $(n=20)$, and with diverse craniofacial syndromes $(n=32 ; 11$ Crouzon, 11 Apert, 7 Pfeiffer, 2 Saethre-Chotzen, and 2 clover-leaf skull). We used the classification of Whitaker et al. to evaluate the surgical results. Complications of each technique and time of patients' hospitalization were also recorded. The surgeries were classified in 12 different types according to the techniques used. Type I comprised endoscopic assisted osteotomies for sagittal synostosis (42 cases). Type II included sagittal suturectomy and expanding osteotomies (46 cases). Type III encompassed procedures similar to type II but that included frontal dismantling or frontal osteotomies in scaphocephaly (59 cases). Type IV referred to complete cranial vault remodelling (holocranial dismantling) in scaphocephaly (13 cases). Type $\mathrm{V}$ belonged to fronto-orbital remodelling without fronto-orbital bandeau in trigonocephaly (50 cases). Type VI included fronto-orbital remodelling without fronto-orbital bandeau in plagiocephaly (14 cases). In Type VII cases of plagiocephaly with frontoorbital remodelling and fronto-orbital bandeau were comprised (14 cases). Type VIII consisted of occipital advancement in posterior plagiocephaly (1 case). Type IX included standard bilateral fronto-orbital advancement with expanding osteotomies (30 cases). Type $\mathrm{X}$ was used in multi-suture craniosynostosis (15 cases) and consisted of holocranial dismantling (complete cranial vault remodelling). Type XI included occipital and suboccipital craniectomies in multiple suture craniosynostosis (10 cases) and Type XII instances of fronto-orbital

Recibido: 15-01-8. Aceptado: 19-02-08 distraction (26 cases).

Results. The mortality rate of the series was 2 out of 283 cases $(0.7 \%)$. These 2 patients died one year after surgery. All complications were resolved without permanent deficit. Mean age at surgery was 6.75 months. According to Whitaker et al's classification, 191 patients were classified into Category I (67.49\%), 51 into Category II (18.02\%), 30 into Category III (10.6\%) and 14 into Category IV (4.90\%). Regarding to craniofacial conformation, $85.5 \%$ of patients were considered as a good result and $15.5 \%$ of patients as a poor result. Of the patients with poor results, $6.36 \%$ were craniofacial syndromes, $2.12 \%$ had anterior plagiocephaly and $1.76 \%$ belonged to non-syndromic craniosynostosis.

The most frequent complication was postoperative hyperthermia of undetermined origin (13.43\% of the cases), followed by infection $(\mathbf{7 . 5 \%})$, subcutaneous haematoma $(5.3 \%)$, dural tears $(5 \%)$, and CSF leakage $(2.5 \%)$. The number of complications was higher in the group of re-operated patients $(12.8 \%$ of all). In this subset of reoperations, infection accounted for $62.5 \%$, dural tears for $93 \%$ and CSF leaks for $75 \%$ of the total. In regard to the surgical procedures, endoscopic assisted osteotomies presented the lowest rate of complications, followed by standard fronto-orbital advancement in multiple synostosis, trigonocephaly and plagiocephaly. The highest number of complications occurred in complete cranial vault remodelling (holocranial dismantling) in scaphocephaly and multiple synostoses and after the use of internal osteogenic distractors. Of note, are two cases of iatrogenic basal encephalocele that occurred after combined fronto-facial distraction.

Conclusions. The best results were obtained in patients with isolated craniosynostosis and the worst in cases with syndromic and multi-suture craniosynostosis. The rate and severity of complications were related to the type of surgical procedure and was higher among patients undergoing re-operations. The mean time of hospitalization was also modified by these factors. Finally, we report our considerations for the management of craniosynostosis taking into account each specific tech- 
nique and the age at surgery, complication rates and the results of the whole series.

KEY WORDS: Craniosynostosis. Craniofacial surgery treatment. Craniofacial surgery results. Craniofacial surgery complications.

Tratamiento quirúrgico de las craneosinostosis aisladas y sindrómicas. Resultados y complicaciones en $\mathbf{2 8 3}$ casos consecutivos

Resumen

Objetivos. Revisar y analizar los resultados y las complicaciones del tratamiento en nuestra serie de 283 casos consecutivos de craneosinostosis, tratados por medio de 330 procedimientos quirúrgicos transcraneales entre los años 1999 hasta el 2007.

Pacientes y métodos. La serie consta de 155 escafocefalias, 50 trigonocefalias, 28 plagiocefalias anteriores, 1 plagiocefalia occipital, 20 craneosinostosis múltiples no sindrómicas y 32 síndromes craneofaciales (11 Crouzon, 11 Apert, 7 Pfeiffer, 2 Saethre-Chotzen y 2 cráneos en hoja de trébol). Para la evaluación de los resultados quirúrgicos hemos empleado la conocida clasificación de Whitaker. Por otra parte, para el estudio de las complicaciones, los procedimientos quirúrgicos utilizados se han clasificado en 12 tipos: Tipo I: osteotomías asistidas por endoscopia en las escafocefalias (42 casos). Tipo II: suturectomía sagital y osteotomías expansivas (46 casos). Tipo III: la misma técnica que en el grupo anterior, pero incluyendo el desmontaje frontal o bien osteotomías de la región frontal en escafocefalias (59 casos). Tipo IV: remodelación completa de la bóveda craneal (desmontaje holocraneal) en escafocefalias (13 casos). Tipo V: remodelación fronto-orbitaria sin barra fronto-orbitaria en trigonocefalias (50 casos). Tipo VI: remodelación fronto-orbitaria sin barra frontoorbitaria en plagiocefalias anteriores (14 casos). Tipo VII: remodelación fronto-orbitaria con barra frontoorbitaria en plagiocefalias anteriores (14 casos). Tipo VIII: avance occipital en plagiocefalias posteriores (1 caso). Tipo IX: avance fronto-orbitario standard con osteotomías expansoras (30 casos). Tipo $\mathrm{X}$ : desmontaje holocraneal (remodelación completa de la bóveda craneal) en craneosinostosis múltiples (15 casos). Tipo XI: craneotomías occipitales y craniectomías de fosa posterior en craneosinostosis múltiples (10 casos). Tipo XII: distracción fronto-orbitaria (26 casos). Los datos de la estancia media de los pacientes también se han calculado según el tipo de procedimiento.

Resultados. La mortalidad de la serie fue de $\mathbf{2}$ casos entre 283 pacientes. Todas las complicaciones se resolvie- ron sin déficits aparentes y la edad media de la serie en la primera intervención fue de 6.75 meses. Globalmente y siguiendo la escala de Whitaker, 191 pacientes se clasificaron en Categoría I (67,49\%), 51 en la Categoría II $(\mathbf{1 8 , 0 2 \%}), 30$ en la Categoría III (10,6\%) y 14 en la Categoría IV (4,90\%). Es decir, en el 85,5\% de los pacientes se obtuvo un buen resultado en cuanto al grado de mejoría de la morfología craneofacial mientras que en el $\mathbf{1 5 , 5 \%}$ el resultado fue considerado como pobre. De estos últimos pacientes casi la mitad de los casos $(6,36 \%)$ eran síndromes craneofaciales, el 2,12\% plagiocefalias anteriores y el $1,76 \%$ craneosinostosis múltiples no sindrómicas. La complicación más frecuente fue la hipertermia posoperatoria no filiada $(13,43 \%)$, seguida por las infecciones $(7,5 \%)$, los hematomas subcutáneos $(5,3 \%)$, los desgarros durales $(5 \%)$ y las fístulas de LCR (2,5\%). La frecuencia y el tipo de complicaciones aumentaron en número e importancia en el grupo de pacientes reoperados $(12,8 \%$ de toda la serie): $62,5 \%$ de todas las infecciones, $93 \%$ de los desgarros durales y 75\% de las fístulas de LCR. Considerando los procedimientos quirúrgicos, las osteotomías asistidas por endoscopia en las escafocefalias fueron los que tuvieron menos complicaciones, seguidos de los avances frontoorbitarios standard en las craneosinostosis múltiples, las trigonocefalias y las plagiocefalias anteriores. Los desmontajes holocraneales, tanto en las escafocefalias como en las craneosinostosis múltiples, fueron los que tuvieron complicaciones más frecuentes, así como las técnicas de distracción fronto-orbitaria.

Conclusiones. Los mejores resultados se obtuvieron en las craneosinostosis aisladas y los peores en las craneosinostosis múltiples y sindrómicas. El porcentaje y la gravedad de las complicaciones tuvieron relación con el tipo de procedimiento quirúrgico, siendo además más frecuentes e importantes en los pacientes reintervenidos. La estancia media también se comportó siguiendo estos parámetros.

Finalmente, hemos podido establecer una serie de normas para el tratamiento de las craneosinostosis, basados en la edad de los pacientes, los resultados y las complicaciones de cada técnica quirúrgica.

PALABRAS CLAVE: Craneosinostosis. Cirugía cráneofacial, tratamiento. Cirugía cráneofacial, resultados. Cirugía cráneofacial, complicaciones.

Introduction

The diagnosis and treatment of craniosynostosis during the last decade have been improved by new and different techniques for diagnosis and surgical treatment. The use of 3-dimensional computerized tomography (3-D CT) allows 
for a better vision of the skull, mostly of the cranial base. With the new magnetic resonance imaging (MRI) we can see the anatomic alterations of the posterior region of the skull and ascertain their role in the pathophysiology of intracranial hypertension, especially in syndromic craniosynostosis ${ }^{38,40}$. Intracranial pressure (ICP) monitoring enables the establishment of an appropriate management of these patients. On the other hand, there is no doubt that reabsorbable osteosynthesis has improved the stability of the cranial assemblies, osteogenic distraction has contributed to find further indications in these treatments, and endoscopic approaches have made some of these procedures less invasive $e^{5,24,26,27}$.

Nevertheless, some problems regarding treatment of craniosynostosis still remain unanswered $\mathrm{d}^{6,22,30,37}$. Although some reports have addressed the global results of craniosynostosis management ${ }^{16,17,41}$, most of them are from the last decade of the $20^{\text {th }}$ century ${ }^{29,30,41}$ and, in our opinion, they are not sufficient to establish a universal accepted algorithm of treatment. The scarcity of available publications dealing with complications is also surprising. In addition, most of them are included in clinical series regarding general aspects of the craniosynostoses ${ }^{16,41,44-46}$ or dealing with postoperative infection ${ }^{13,25,48}$.

\section{Objective}

To review our experience on the treatment of 283 patients with craniosynostosis seen during the last 9 years, aiming at establishing an algorithm of treatment based on patients' age at surgery, results and complications arising from the diverse surgical procedures.

\section{Patients and methods}

The files of 283 patients with craniosynostosis who underwent 330 surgical procedures were retrospectively reviewed. Although our Craniofacial Unit started in 1989, our study comprises a 9 year span (from 1999 to 2007). The reasons to choose this period include the widespread use of 3D-CT and MRI for diagnosis, the homogeneity of the surgical techniques utilized and the stability of the staff performing these procedures.

The diagnoses of the 283 cases were scaphocephaly $(\mathrm{n}=155)$, trigonocephaly $(\mathrm{n}=50)$, anterior plagiocephaly $(n=28)$, occipital plagiocephaly $(n=1)$, non-syndromic multi-suture craniosynostosis $(\mathrm{n}=20)$, and 31 craniofacial syndromes (11 Crouzon, 11 Apert, 5 Pfeiffer, 2 SaethreChotzen and 2 cloverleaf skull). Mean age of patients at the surgery was 6.75 months. All patients underwent transcranial procedures, such as diverse craniectomies and osteotomies. Reoperations accounted for 37 of 330 surgical procedures $(11.5 \%)$ that were performed for unsatisfactory results or relapse. Ten of these procedures were done at the time of the initial treatment (posterior fossa craniectomy and occipital dismantling). Cases of facial advancement were not included in this series. All children received at least two doses of anti-pneumococcal vaccine. Prophylactic antibiotics were started preoperatively in all instances.

We employed the classification of Whitaker and associates $^{45}$ to evaluate the surgical results:

Category I: no refinements or surgical revisions considered advisable or necessary.

Category II: soft-tissue or lesser bone-contouring revisions advisable apt to be performed on an outpatient basis or requiring a maximum of 2-day hospitalization.

Category III: major alternative osteotomies or bonegrafting procedure advisable, i.e., orbital repositions, onlay bone grafts, being these procedures not so extensive as the original operations.

Category IV: a major craniofacial procedure advisable, duplicating or exceeding the original operation.

Complications were classified as cranial or extracranial, including those presenting for a long time-span that ranged from the immediate postoperative period to long-lasting craniolacunia appearing years after treatment. Only osteosynthesis reabsorbable material was used. Infection was considered as cranial when either local signs of infection or subgaleal or intracranial swelling with concomitant fever were detected. Therefore, cultures may have been negative as prophylactic antibiotics were used. On the other hand, to consider an infection as extracranial, cultures must have been positive. Some cases were diagnosed with postoperative fever of undetermined origin when the patients showed a higher than $38^{\circ}$ body temperature during the first postoperative days, in the absence of local signs of infection or positive cultures. To complete this study, the mean hospital stay was evaluated relating it to each surgical procedure.

Surgical procedures were classified into 11 different types:

Type I: scaphocephaly. Endoscopic-assisted suturectomy and osteotomies. We started using this technique in 2003, having treated by this method 42 children whose mean age at surgery was of 4.14 months. The surgical technique (Fig.1) has been previously reported ${ }^{24,25}$.

Type II: scaphocephaly. Suturectomy and expanding osteotomies. Standard technique (Fig.2): sagittal suturectomy and green-stick parieto-temporal and occipital osteotomies were performed through a bicoronal incision. This technique includes 46 cases whose mean age was 6.26 months.

Type III: scaphocephaly. Suturectomy and expanding osteotomies including frontal bone remodelling (Fig.2). In cases with severe frontal bulging, shell osteotomies in the frontal bone or complete dismantling and remodelling were added to the standard technique (type III). We opera- 


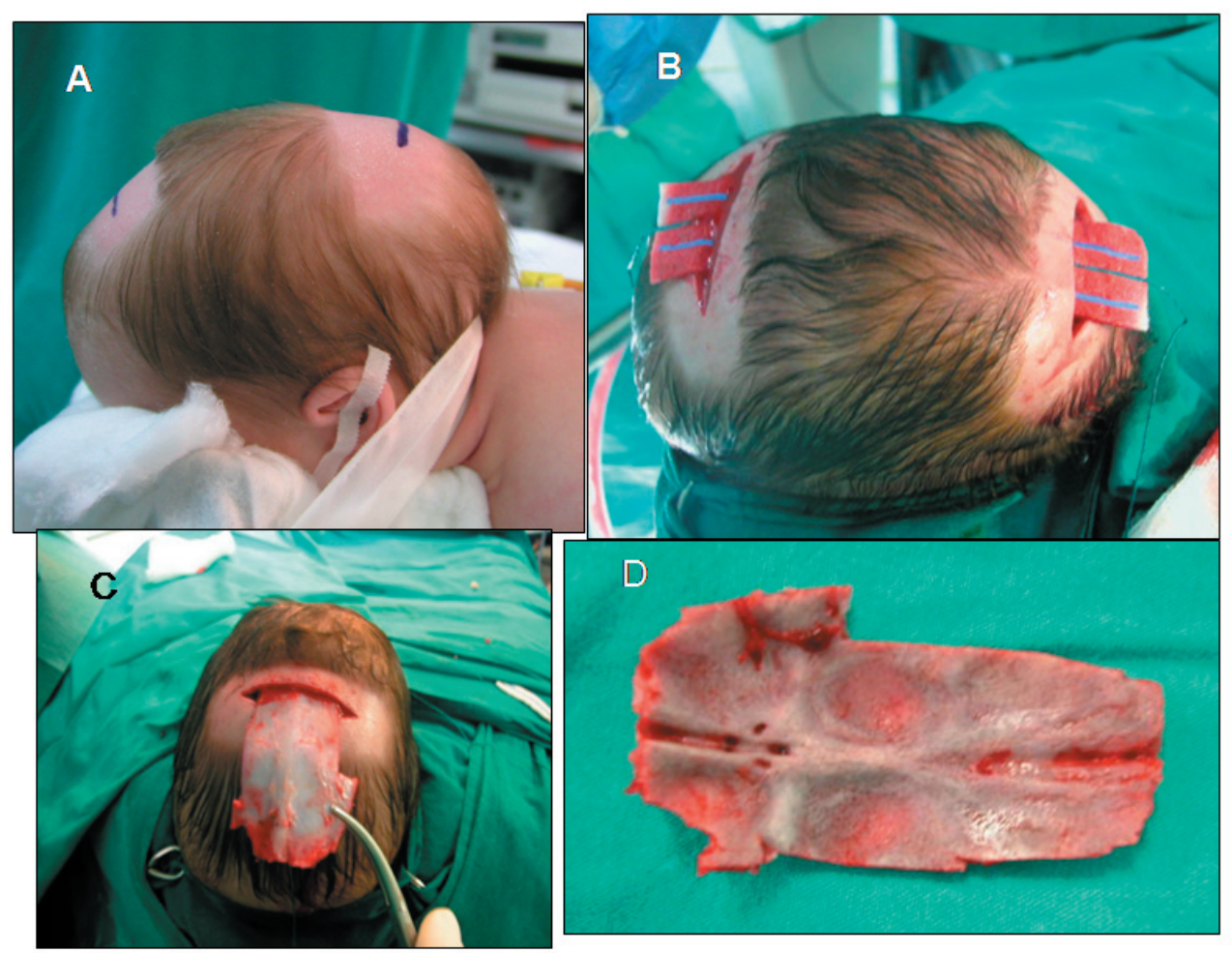

Figure 1. Type I: scaphocephaly. Endoscopic-assisted suturectomy and osteotomies. A: patient resting in modified prone position. B: surgical patties showing subcutaneous dissection. C: sagittal suture excision complete. D: excised sagittal suture showing characteristic grooving of the superior sagittal sinus.

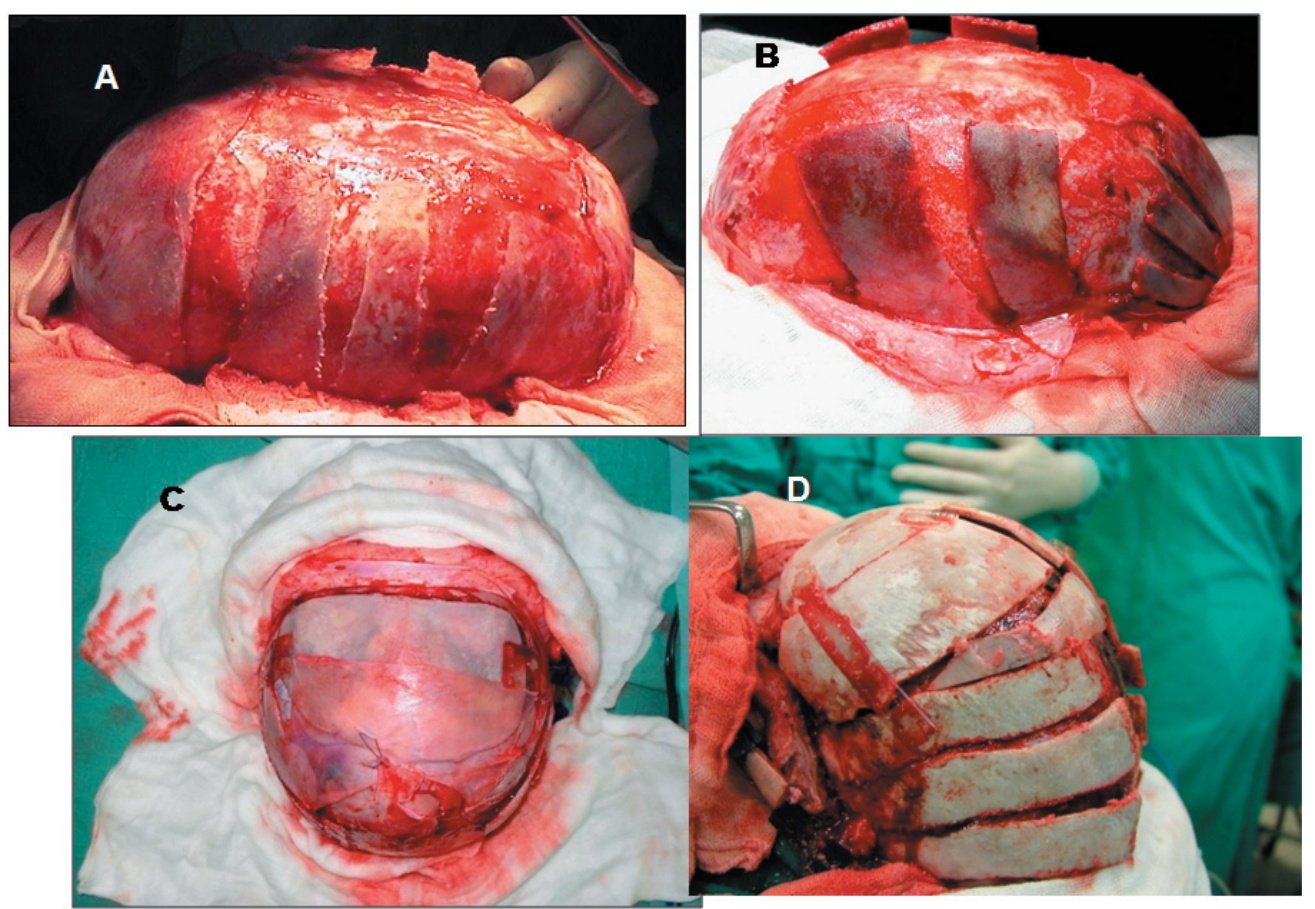

Figure 2. Scaphocephaly. A: Type II. Suturectomy and expanding osteotomies. Standard technique. B and C: Type III and IV. Scaphocephaly. Suturectomy and expanding osteotomies including frontal bone remodelling. D: total cranial vault remodelling (holocranial dismantling). 


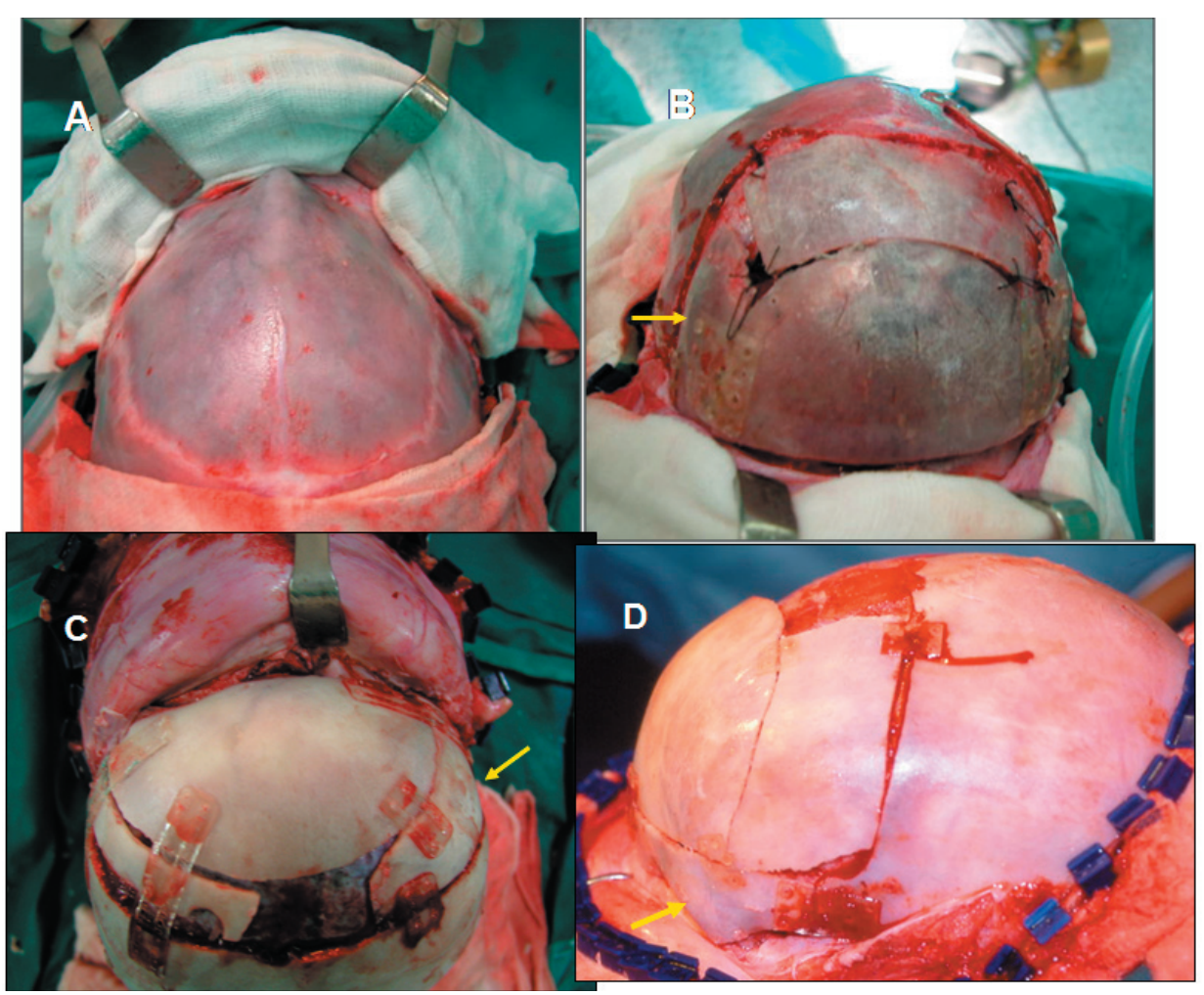

2008; 19: $509-529$

Figure 3. A and B: Type V: trigonocephaly. Frontal remodelling without fronto-orbital "bandeau". The arrow shows the bone pieces necessary for a proper assembly. C: Type VI: anterior plagiocephaly. Frontal bilateral remodelling without fronto-orbital "bandeau". D: Type VII: anterior plagiocephaly. Frontal bilateral remodelling with fronto-orbital "bandeau". Note: the fronto-orbital "bandeau" (arrow).

ted with this procedure 59 patients (mean age 6.5 months) including 3 reoperations.

Type IV: Scaphocephaly. Total cranial vault remodelling (holocranial dismantling) consisted of sagittal and bicoronal suturectomies with wide craniotomies for complete remodelling of the cranial vault. We usually carried out this technique in a single stage, changing the child's position from supine to modified prone (Fig.2). It was performed in 13 patients (mean age 10.5 months).

Type V: Trigonocephaly. Frontal remodelling without fronto-orbital "bandeau" (Fig.3). This technique has already been reported from our department ${ }^{23,32}$ and consisted of a very low bilateral fronto-orbital craniotomy, drilling of the supra-orbital eminences and transposition of a selected parietal bone. 56 patients (mean age 6.65 months) were operated with this technique including 2 reoperations.

Type VI: anterior plagiocephaly. Frontal bilateral remodelling without frontal-orbital "bandeau". The technique is similar to the previously described ${ }^{32}$ and included an extensive pterional resection. It was used in 16 cases ( 3 reoperations) with a mean patients' age at surgery of 10 months.

Type VII: anterior plagiocephaly. Frontal bilateral remodelling with frontal-orbital "bandeau". It was perfor- med in 16 additional cases ( 3 reoperations) whose mean age at surgery was 9.5 months. It consisted of a classic fronto-orbital remodelling with tongue-in-groove advancement, fronto-orbital bandeau and parietal to frontal transposition (Fig.3).

Type VIII: occipital plagiocephaly. Occipital remodelling was performed in a single case by occipital bilateral craniotomy.

Type IX: standard bilateral fronto-orbital advancement with expanding osteotomies (Fig.4) consisted of standard bilateral fronto-orbital advancement with or without fronto-orbital bandeau plus expanding fronto-parietal osteotomies. This method was performed in 30 patients ( 8 reoperations) with a mean age of 9 months and comprised 10 cases with non-syndromic multi-suture craniosynostosis and 15 with craniofacial syndromes (5 Crouzon, 5 Apert, 3 Pfeiffer and 2 Saethre-Chotzen).

Type X: holocranial dismantling (total vault remodelling) in multiple craniosynostosis (Fig.4). It consisted of extensive frontal, parietal and occipital craniotomies to achieve a complete vault remodelling performed through a bicoronal incision. As in type $\mathrm{V}$ technique used for scaphocephaly, the patient is changed from supine to prone position in the same surgical session. Fifteen children $(8$ 


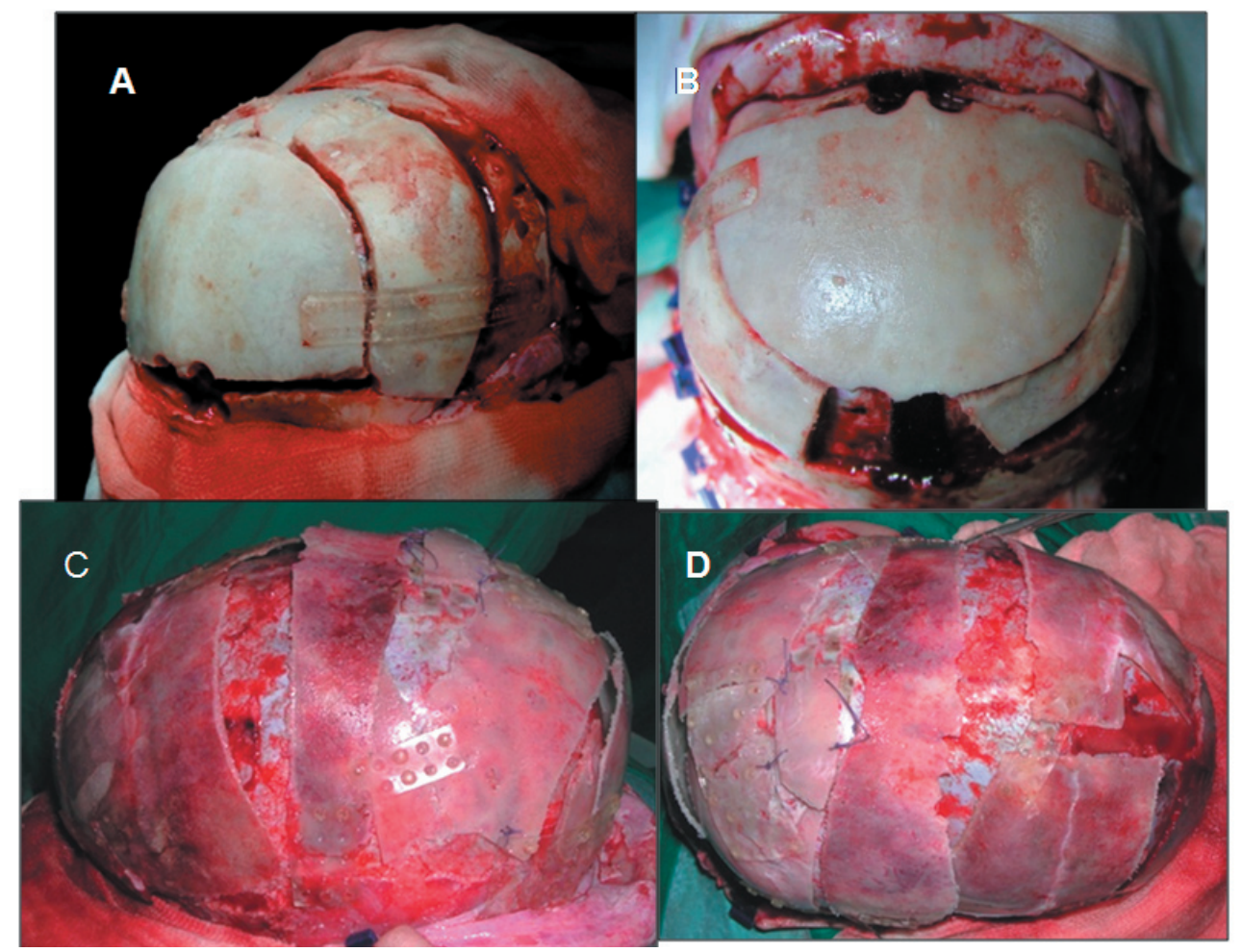

Figure 4. A and B: Type IX. Standard bilateral fronto-orbital advancement. C and D: Type X. Holocranial dismantling (total vault remodelling).

reoperations, mean age of 8.5 months) were treated with this technique, 4 with multiple non-syndromic craniosynostosis, 8 with Crouzon's and 2 with Apert's syndromes.

Type XI: posterior fossa (sub-occipital) craniectomies and occipital dismantling. It was performed in 10 cases for the treatment of multiple synostosis of the posterior region of the skull. Three children suffered from multi-suture nonsyndromic craniosynostosis and 7 from craniofacial syndromes (3 with Crouzon's, 1 with Apert's, 1 with Pfeiffer's syndrome and 2 with cloverleaf skull). All of them had tonsillar herniation at MRI, 2 cases presented cervical syringomyelic cavities and 7 cases developed hydrocephalus. Due to huge venous anomalies of the posterior fossa only in 3 cases could a dural opening be accomplished.

Type XII: internal osteogenic distraction techniques. They were used only for fronto-orbital distraction. Patients with scaphocephaly or trigonocephaly that underwent internal distraction were few and were not included in the series. Internal osteogenic distraction was started in our unit in 2004. 26 cases (mean age 10 months) were operated on, 7 with anterior plagiocephaly, 4 with multi-suture non-syndromic craniosynostosis and 15 with craniofacial syndromes, including 5 Crouzon, 6 Apert and 4 Pfeiffer instances. Reabsorbable material was used in all but two patients. We used 2 distractors over the affected coronal suture in anterior plagiocephaly. In multi-suture synostosis,
4 distractors (2 to each side) were most frequently used. Fronto-orbital distractors combined with mid-face distraction were used in 5 cases with craniofacial syndromes to complete modified "mono-bloc" advancement (3 cases with internal mid-face and 2 with external distractors). Internal distraction as a rescue technique after an unsatisfactory result or after relapse was utilized in 9 cases.

Hydrocephalus. Associated hydrocephalus was found and treated with a VP shunt in 22 patients (Table III).

ICP monitoring. Twenty-five patients underwent a 48hour ICP recording by an ICP intraparenchymal sensor.

\section{Results}

(Tables I, II, III). Two patients died 1 year after the initial surgery. The first one was an 18-month-boy with Pfeiffer syndrome and cloverleaf skull, who died of recurrent respiratory infections related to tracheotomy. The second patient, a boy with Pfeiffer syndrome, developed a basal encephalocele after a modified monobloc craniofacial advancement and died of fulminant meningitis 1.5 years after the transcranial encephalocele repair.

Rating of the cases (Table I) was done after the initial treatment and, although some cases had been re-operated, these were not rated again in the present series. As a whole, and according to Whitaker et al.'s scale ${ }^{45}, 191$ (67.49\%) 


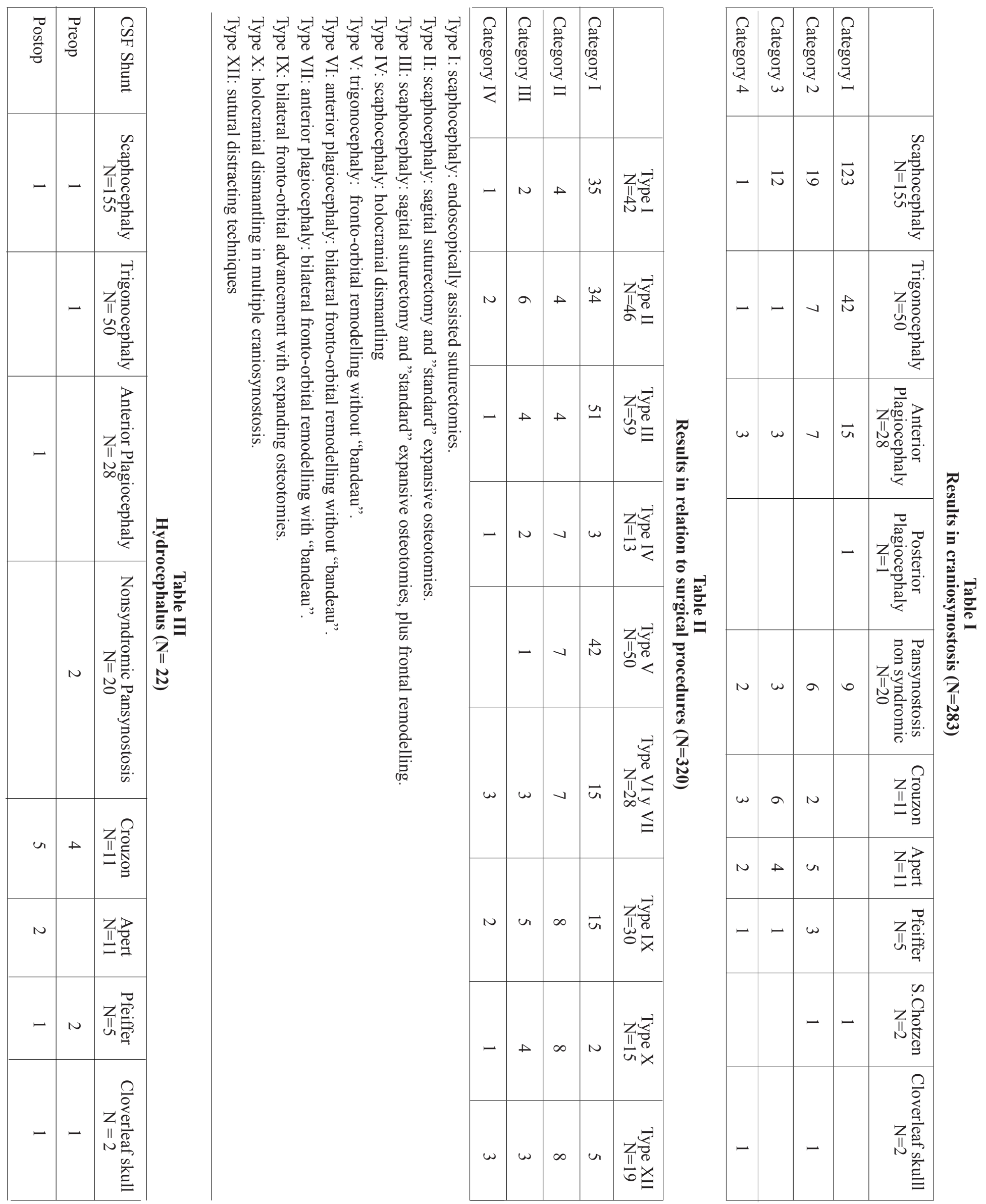


patients were classified into Category I, 51 (18.02\%) into Category II, 30 (10.6\%) into Category III and 14 (4.90\%) into Category IV. In short, $85.5 \%$ of the patients were considered to have attained a good result regarding craniofacial conformation and $15.5 \%$ as a poor result (Table I). Of these unsatisfactory results, $6.36 \%$ of patients belonged to craniofacial syndromes, $2.12 \%$ to cases with anterior plagiocephaly and $1.76 \%$ to instances of multiple non-syndromic craniosynostosis.

Regarding the diverse diagnostic group, the worst results were seen in craniofacial syndromes $(58 \%$ of categories III and IV) followed by multiple non-syndromic craniosynostosis (25\%) and anterior plagiocephaly (21.4\%). The best results were achieved in patients with trigonocephaly $(92 \%)$ and scaphocephaly $(91.6 \%)$.

The results were also analyzed considering the surgical technique applied (Table II).

\section{Scaphocephaly}

123 cases of scaphocephaly were rated into Category I, 19 into Category II, 12 into Category III and 1 into Category IV, being $91.6 \%$ of them rated as the best categories with only $8.38 \%$ regarded as a poor result. These unsatisfactory results were related to insufficient correction of frontal bossing. Forty two children (mean age at surgery of 4.14 months) were operated with endoscopic-assisted suturectomy and osteotomies (Type I procedure). Thirty five cases were rated into category I, 4 into category II, 2 into category III and 1 into category IV. Thirty five children underwent postoperative helmet therapy.

Forty six children with a mean age of 6.26 months were operated by suturectomy and expanding osteotomies (Type II procedure or standard technique) and 34 cases were rated as category I, 4 as category II, 5 as category III and 2 as category IV. Fifty nine children (mean age 6.5 months) with severe frontal bulging were submitted to suturectomy and expanding osteotomies including frontal bone remodelling (Type III procedure ), 51 were rated into category I, 4 into category II, 4 into category III y 1 into category IV. Finally, in 13 cases a Type IV procedure with total cranial vault remodelling was performed (holocranial dismantling). Three of these cases were rated into category I, 7 into category II, 2 into category III and 1 into category IV.

\section{Trigonocephaly}

Fifty children with trigonocephaly underwent a Type $\mathrm{V}$ procedure consisting of frontal remodelling without fronto-orbital "bandeau". Forty four of them were classed as category I, 7 as category II and 1 as category III. The children $(n=8)$ that were not rated into category I presented mild "narrowing" of the new frontal bone probably due to the placement of a too narrow parietal template.
Anterior plagiocephaly

This subset comprised 28 patients who were rated as follows: 15 fell into category I, 7 into category II, 3 into category III and 3 into category IV. Latterly, 6 children were considered as a poor end-result. Ten cases were treated by frontal bilateral remodelling without frontal-orbital "bandeau" (Type VI procedure) and a further 11 children with type VII procedure (bifrontal remodelling with frontoorbital "bandeau"). The mean age at surgery of the first group was 10 months and that of the second 9.5 months. There were no major differences in the results of the two groups; nevertheless the type VI procedure was applied in minor and moderate cases. Fronto-orbital advancement with an osteogenic distractor was performed in 7 cases, 3 of them were rated into category II, 2 into category III, and 2 into category IV. Orbital dystopia and pterional hollowing were the main factors leading to a bad result. A permanent deviation of the nasal axis was observed in 6 patients considered as a bad result.

\section{Occipital plagiocephaly}

Only a 4-year-old boy was treated of true unilateral occipital plagiocephaly and attained a good end-result.

Non syndromic multiple craniosynostosis.

This group accounted for a total of 20 cases. Ten children presented unique brachycephaly and were treated with bilateral fronto-orbital advancement, 3 of them with osteogenic distractors. Four patients with turri-brachycephaly were treated with craniofacial advancement; 2 with osteogenic distractors and 2 with a Type IX procedure (standard bilateral fronto-orbital advancement plus expanding osteotomies). Six patients presented with oxycephaly and were operated with holocranial dismantling. The cranial deformation in the last 2 cases was a true bilateral occipital plagiocephaly combined with deformational brachycephaly, that was treated by an occipital remodelling. The outcomes in this group were classified as: category I in 9 children ( 6 with brachycephaly and 3 with turribrachycephaly); category II in 6 cases ( 4 with oxycephaly and 2 with brachycephaly); one case of oxycephaly and 2 of turribrachycephaly fell in category III; and 2 cases into category IV (1 with oxichephaly and 1 with turribrachycephaly).

\section{Craniofacial syndromes}

\section{Crouzon syndrome}

Eleven children with Crouzon's syndrome had oxycephaly and were treated with total vault remodelling $(n=7)$, bilateral fronto-orbital conventional advancement $(n=4)$ and with osteogenic distractors $(\mathrm{n}=2)$. Regarding results, 2 cases were classified as category II, 5 as category III and 4 as category IV. 

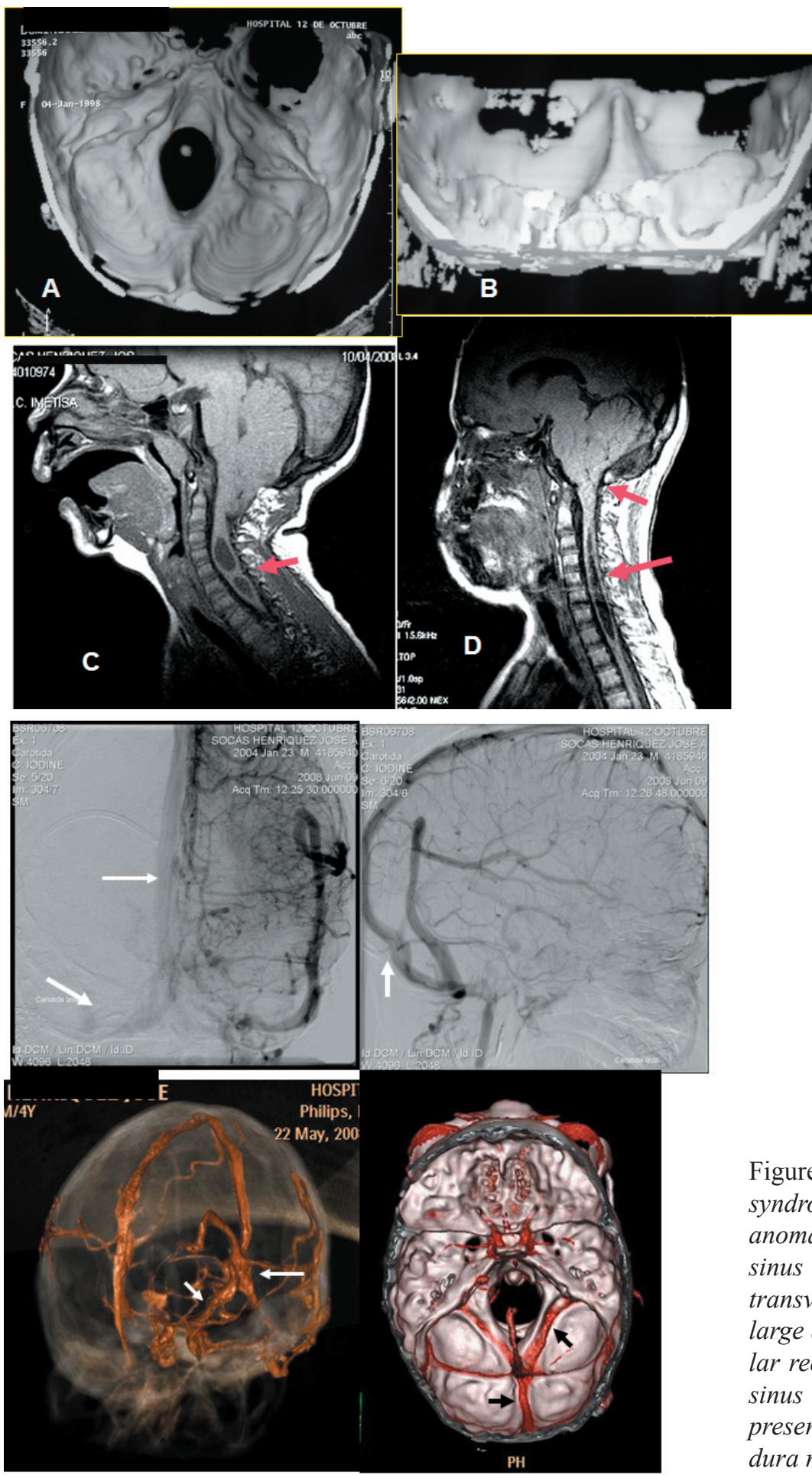

Figure. 5. A and B: posterior fossa in Crouzon syndrome. Bone displasia, bony ridging and spikes are shown. $C$ and D: MRI in two Crouzon patients. Tonsillar herniation and cervical syringomyelia.
Figure. 6. A and B: carotid angiography in Crouzon's syndrome, venous phase. Arrows point diverse venous anomalies. The torcula does not exist and the sagittal sinus continues towards a large occipital sinus with transverse foramen magnum sinuses. Anomalous large draining vein (double arrow). C and D: vascular reconstruction in the same case. Great occipital sinus and transverse foramen magnum sinuses are present. Intraoperative opening of posterior fossa dura mater was considered impossible.
Apert syndrome

Ten of 11 patients with Apert's syndrome presented turri-brachycephaly and were treated with fronto-orbital advancement, 8 cases with osteogenic distractors and 2 cases with a conventional type IX procedure. One case presented severe oxycephaly and underwent a type XI proce- dure (holocranial dismantling). Five cases were rated into category II, 4 into category III and 2 cases into category IV.

Pfeiffer syndrome

All patients with this syndrome $(\mathrm{n}=5)$ showed turribra- 


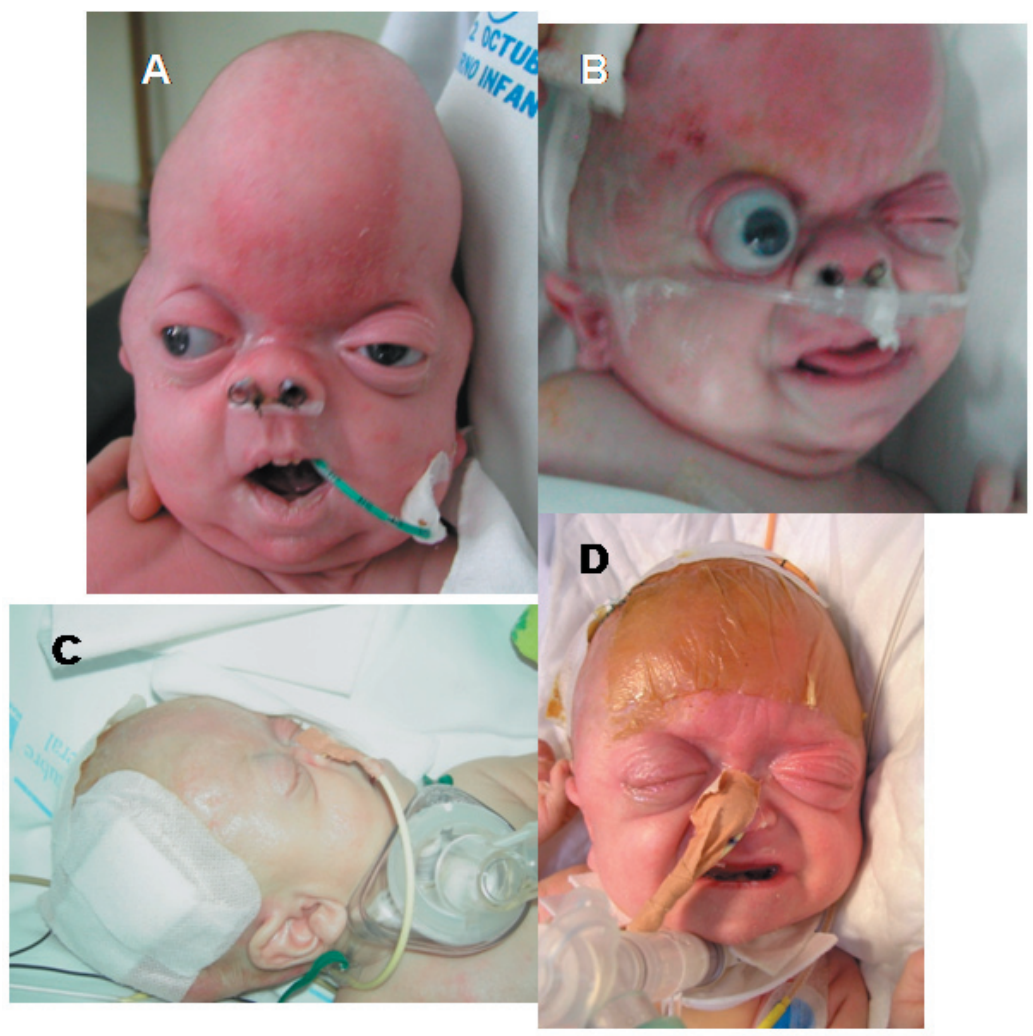

2008; 19:509-529

Figure. 7. Cloverleaf skull in a 3-month toddler. Pfeiffer syndrome. A and B: exophthalmia with globe herniation during Valsalva manoeuvre. C and D: postoperative view after combined fronto-facial distraction. Great improvement was achieved. Unfortunately this child died 18 months later tracheostomyrelated repeated infections.

chycephaly, 2 underwent a standard bilateral fronto-orbital advancement (type IX procedure) and 3 were treated with osteogenic distractors.

\section{Saethre-Chotzen syndrome}

One of the children with this condition underwent bilateral fronto-orbital advancement (type IX procedure) and the other one was treated with osteogenic distractors. The first one was regarded as category I and the second one as category II.

\section{Cloverleaf skull}

There were 2 instances of cloverleaf skull. One was diagnosed with Pfeiffer's syndrome and was treated by fronto-orbital advancement with osteogenic distractors and by cranial decompressing osteotomies. This patient died of tracheotomy-related recurrent rrespiratory infections 1 year after surgery. The second one, diagnosed with Apert's syndrome, was treated with parieto-occipital dismantling and posterior fossa decompression and achieved a good clinical evolution.

In summary, patients with craniofacial syndromes exhibited worse results than those with other types of craniosynostosis (2 patients included into category I, 11 into category II, 11 into category III and 7 into category IV).

\section{Posterior cranial craniosynostosis}

Dural opening could be performed in only 3 of 10 patients treated with occipital dismantling and posterior fossa craniectomy ( 2 with non-syndromic multiple craniosynostosis and 1 with Apert's syndrome). This problem was due to severe anomalies in the venous drainage (Fig. 5-7) and to the presence of huge osseous crests on the inner surface of the skull. All patients improved in regard to shape of the parieto-occipital region and of the rest of the skull (Fig. 8). Tonsillar herniation that was present in 2 instances improved after the surgeries as shown by MRI.

\section{Hydrocephalus}

(Table III). Twenty two children (7.7\% of the whole series) were given a VP shunt for treatment of associated hydrocephalus. Eighteen patients presented multiple craniosynostosis, especially instances of Crouzon's syndrome (9 of 11 operated Crouzon cases). A CSF shunt was inserted before surgical correction of the craniosynostosis in 12 patients and after the cranial procedure in 10 further instances. Two patients developed postoperative shunt infections that evolved satisfactorily.

\section{ICP monitoring}

ICP was recorded in 25 patients with craniosynostosis. ICP monitoring was performed before the first cranial procedure in 10 patients and prior to the treatment of the relapse in 15 . Twenty children, especially those with Crouzon's syndrome, presented intracranial hypertension. 


\section{Complications}

(Tables IV, V, VI). Cases treated with a type IX procedure (posterior fossa craniectomy) and the single case of occipital plagiocephaly (type VIII) were not included in the evaluation of complications because we consider that they underwent a different and special type of surgery.

\section{Intracranial complications}

(Table IV). There were 14 instances of wound infection, 17 of non-infected subgaleal haematoma and 11 of infected subgaleal haematoma, needing all of them surgical drainage. Two cases had an intracranial empyema that was surgically treated. A dural tear was produced in 15 surgeries that was repaired "in situ". We experienced 8 CSF leaks with subgaleal collections (6 treated conservatively, 2 with a lumbar drainage and 1 with associated hydrocephalus treated with VP shunting). One case of cerebral contusion was managed conservatively. There were 2 instances of basal encephalocele complicating modified monobloc advancement. Seven patients with persistent craniolacunia required further surgeries. Three patients presented skin scarring due to plate implants and 1 patient manifested a granulomatous reaction to the resorbable material. In summary, the infection rate for the whole series was $7.5 \%$, accounting subgaleal haematomas for $5.3 \%$ of infectious complications. Dural tears occurred in $5 \%$ of the cases and a CSF leakage in $2.5 \%$.
Figure 8. Cloverleaf skull in a 5-month toddler (Apert syndrome). A: characteristic cloverleaf skull. B: MRI showing cranial conformation. Severe compromise of the parieto-occipital area (arrow). Brain herniation through the anterior region of the skull. Hydrocephalus is present. C: MRI after parieto-occipital remodelling: the anterior aspect of the skull has improved its appearance. D: postoperative aspect of the patient after parietal-occipital remodelling and expanding posterior fossa craniectomy performed in a second stage.

\section{Extracranial complications}

(Table V). Postoperative hyperthermia of undetermined origin was found in 43 cases (13.43\%). Central venous line infections were present in 7 cases $(5.3 \%)$, respiratory tract infections in $10(3.1 \%)$ and urinary tract infections in $9(2.8 \%)$. Other complications were rare.

\section{Complications in reoperations}

(Table VI). A reoperation was performed in 37 patients $(11.56 \%), 21$ diagnosed with multiple craniosynostosis. Complications in this group were more frequent than in the whole series. There were 8 cases of surgical wound infection, 9 of subgaleal haematoma (3 with infection), 2 of empyema, 13 with dural tears, 6 with a CSF leakage, 1 of cerebral contusion, and 2 of basal encephalocele. There were a total of 15 infections, accounting for $62.5 \%$ of infectious complications of the series. A dural tear occurred in 14 patients and a CSF leakage in 6, accounting for 93\% and $75 \%$ respectively of these complications in the whole series. The two cases of basal encephalocele and the one with cerebral contusion also belonged to this particular group.

\section{Complications in relation to the surgical technique}

A detailed account of the complications arising from each type of surgery is given below and in Table IV.

Type I: scaphocephaly treated with endoscopy-assisted osteotomies (42 cases). There was a wound infection and an infected subgaleal haematoma in the same patient that required surgical drainage. 


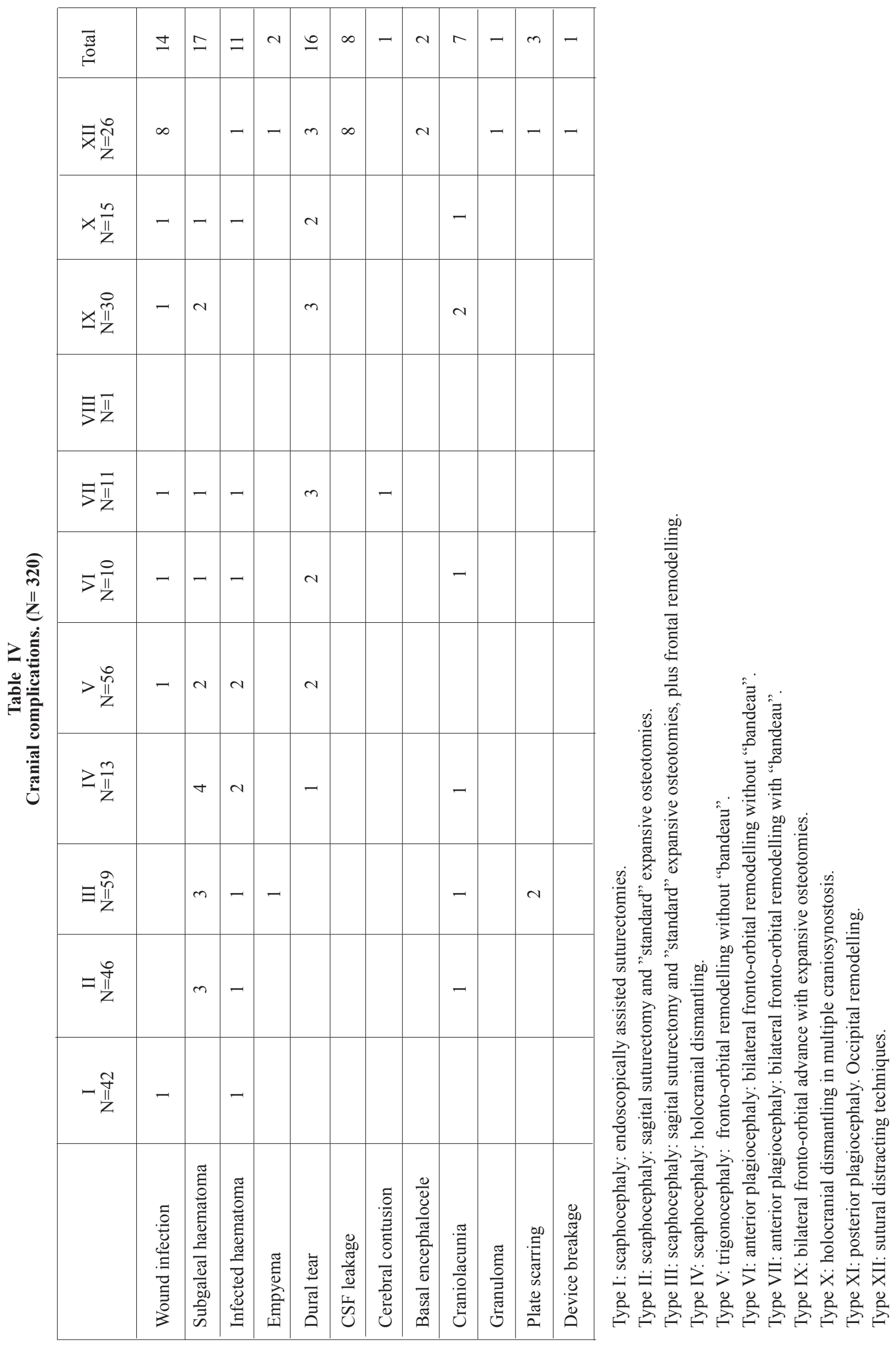




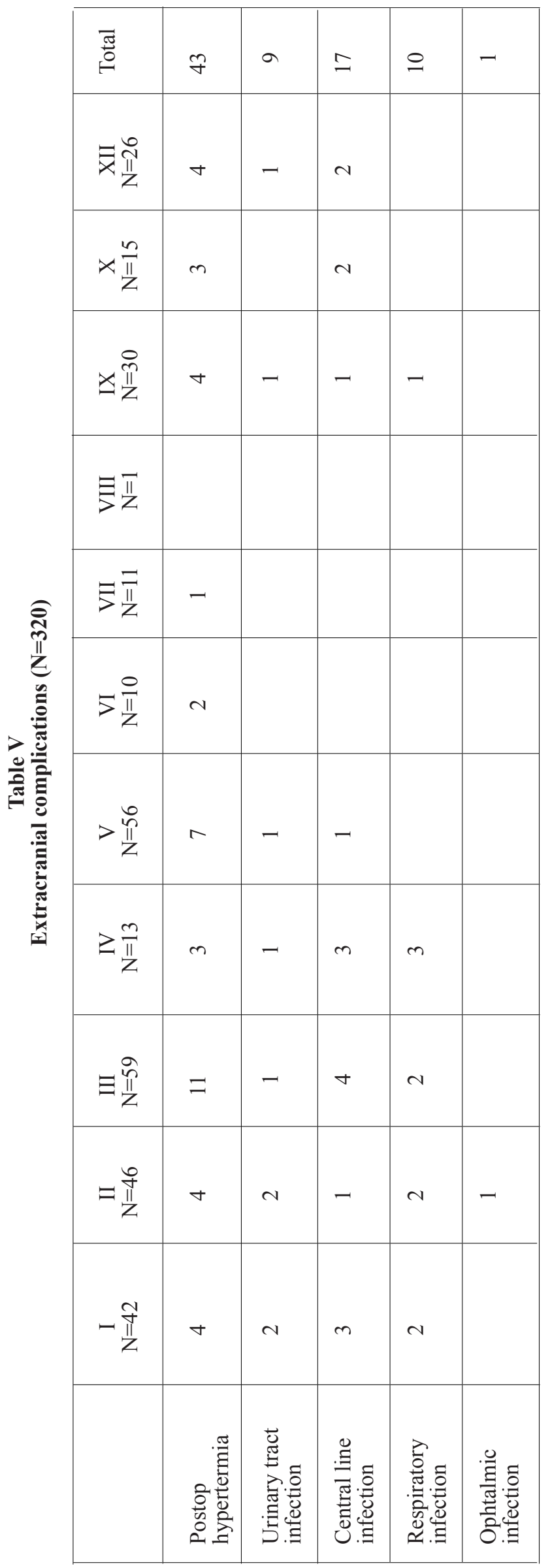

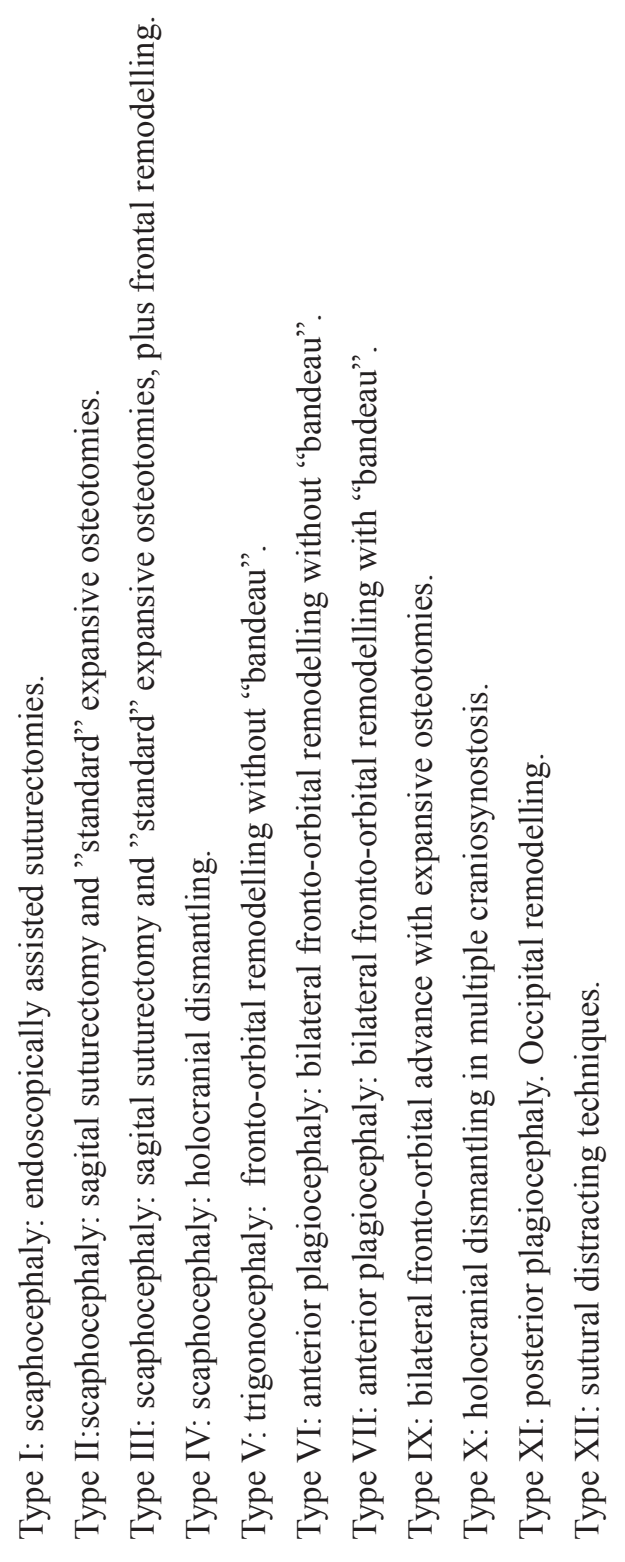




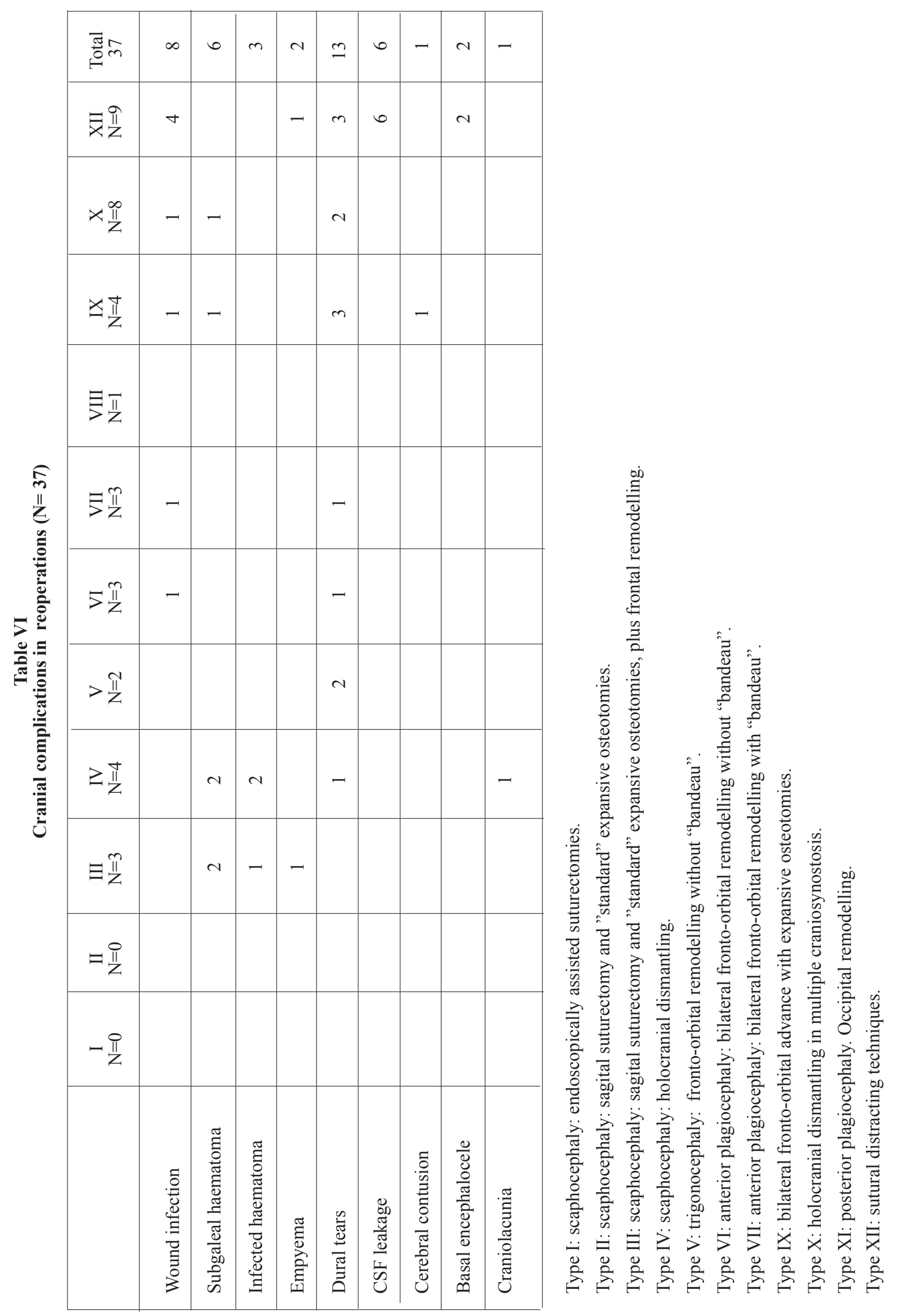




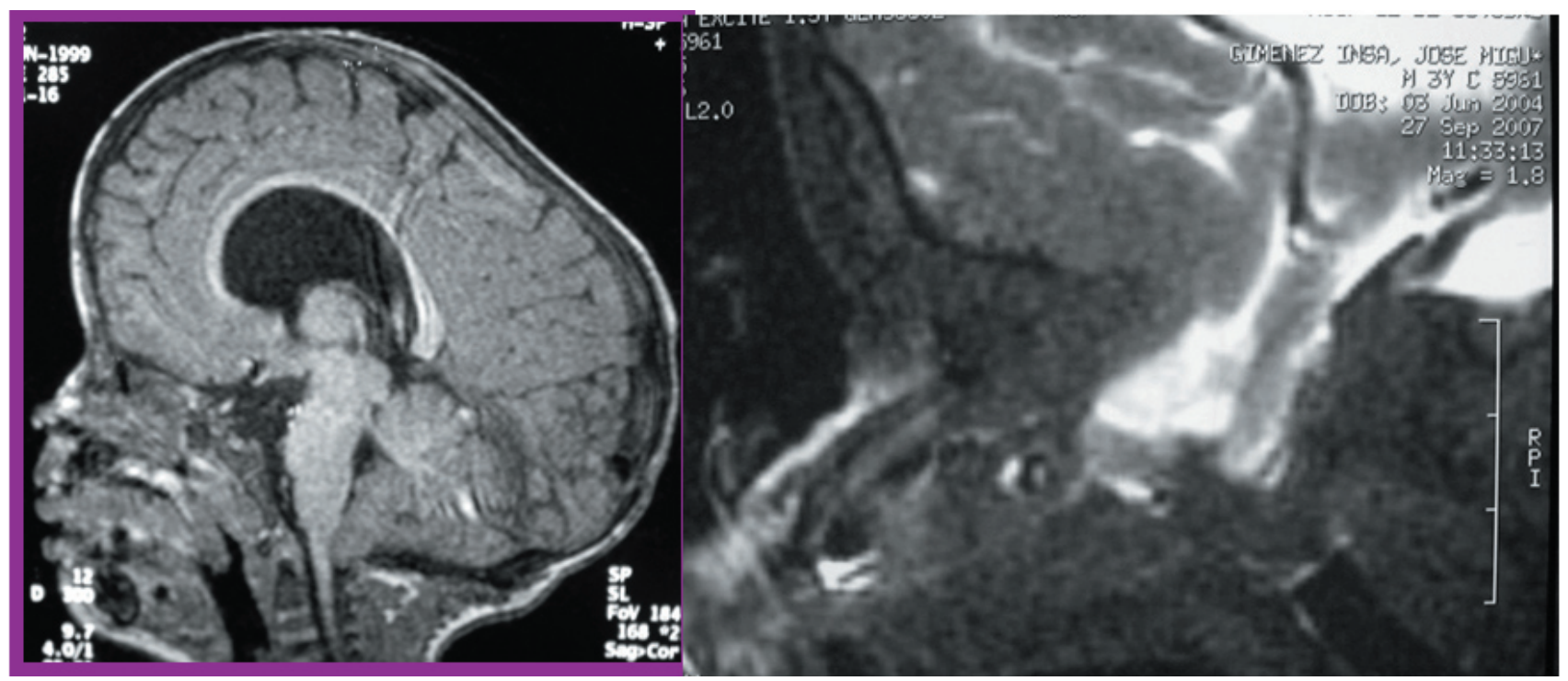

Figure 9. Left: MRI in a Pfeiffer syndrome patient before treatment. Oxicephaly and hydrocephalus. Right: MRI performed 2 months after external combined fronto-facial distraction. Basal encephalocele (arrow) is evident.

Type II: scaphocephaly managed with standard suturectomy and expanding osteotomies (46 cases): there were 4 surgically-evacuated subgaleal haematomas (1 infected) and 1 case of persistent craniolacunia.

Type III: scaphocephaly corrected by sagittal suturectomy and expanding osteotomies plus frontal dismantling (59 cases). Complications consisted of: 3 subgaleal haematomas (1 with infection), all of them surgically treated, 1 surgically-evacuated subdural empyema, 1 persistent craniolacunia, and 2 wound dehiscence that solved with local treatment.

Type IV: scaphocephaly treated with total cranial vault remodelling (holocranial dismantling, 13 cases). With this technique we observed 1 dural tear; 4 subgaleal hematomas ( 2 infected) that were surgically evacuated and 1 case of persistent craniolacunia.

Type V: trigonocephaly managed with bilateral frontoorbital remodelling without fronto-orbital "bandeau" (50 cases). In this group we experienced: 2 dural tears and 2 infected subgaleal haematomas that were operated on.

Type VI: anterior plagiocephaly corrected with bilateral frontal remodelling without frontal-orbital "bandeau" (10 cases). This subset of patients experienced 1 wound infection, 2 dural tears and 1 persistent craniolacunia.

Type VII: anterior plagiocephaly managed with frontal bilateral remodelling and fronto-orbital "bandeau" (11 cases). This technique suffered the following complications: 1 wound infection, 2 dural tears, 1 infected haematoma and 1 cerebral contusion (conservatively treated). Seven cases were treated with fronto-orbital distraction.

Type IX: standard bilateral fronto-orbital advancement with expanding osteotomies in multiple craniosynostosis
(30 cases). Complications of this procedure were: 1 wound infection, 2 subgaleal haematoma, 3 dural tears and 2 persistent craniolacunia.

Type X: holocranial dismantling (total vault remodelling) in multiple craniosynostosis (12 cases). In this complex procedure we experienced: 1 wound infection, 2 infected subgaleal haematoma, 3 dural tears and 2 persistent craniolacunia.

Type XII: fronto-orbital distraction (Table 1, 26 cases). There were 8 cases of local infection that was treated with antibiotics, although 3 of them needed withdrawal of the device. One of the cases was complicated by a subdural empyema that required surgical evacuation. There were 3 dural tears that were repaired "in situ" and 8 cases of local CSF leakage (Fig.3). Two of these were treated with external lumbar drainage for 7-days, and one with associated hydrocephalus with a VP shunt. The rest was treated conservatively.

Two cases (one Crouzon and one Apert) were complicated with a basal encephalocele (Fig.9). Both children had been treated by combined fronto-orbital and midface distraction using external devices. The Crouzon's case presented bilateral postoperative proptosis because of bilateral orbital encephalocele while the Apert's case presented nasal CSF discharge in relation to an ethmoidal encephalocele. Both cases required surgical repair with closure of the meningeal and bone defects. The child with Apert's syndrome died 18 months after surgical repair of fulminant meningitis.

The procedure with the lowest rate of complications was endoscopically assisted suturectomiy followed by standard fronto-orbital advancements and fronto-orbital 
Table VII

Mean stay in relation to surgical procedures $(\mathrm{N}=320$, mean stay 11.9 days $)$

\begin{tabular}{|c|c|c|c|c|c|c|c|c|c|c|}
\hline $\begin{array}{c}\text { Type I } \\
\text { N=42 }\end{array}$ & $\begin{array}{c}\text { Type II } \\
\mathrm{N}=46\end{array}$ & $\begin{array}{c}\text { Type III } \\
\mathrm{N}=59\end{array}$ & $\begin{array}{c}\text { Type IV } \\
\mathrm{N}=13\end{array}$ & $\begin{array}{c}\text { Type V } \\
\mathrm{N}=50\end{array}$ & $\begin{array}{c}\text { Type VI } \\
\mathrm{N}=10\end{array}$ & $\begin{array}{c}\text { Type VII } \\
\mathrm{N}=11\end{array}$ & $\begin{array}{c}\text { Type VIII } \\
\mathrm{N}=1\end{array}$ & $\begin{array}{c}\text { Type IX } \\
\mathrm{N}=30\end{array}$ & $\begin{array}{c}\text { Type X } \\
\mathrm{N}=15\end{array}$ & $\begin{array}{c}\text { Type XII } \\
\mathrm{N}=26\end{array}$ \\
\hline 11,22 & 12,4 & 11,5 & 16,2 & 12,9 & 13,2 & 13,2 & 13,5 & 14,6 & 20,5 & 11,9 \\
\hline
\end{tabular}

Type I: scaphocephaly: endoscopically assisted suturectomies.

Type II: scaphocephaly: sagital suturectomy and "standard" expansive osteotomies.

Type III: scaphocephaly: sagital suturectomy and "standard" expansive osteotomies, plus frontal remodelling.

Type IV: scaphocephaly: holocranial dismantling.

Type V: trigonocephaly: fronto-orbital remodelling without "bandeau".

Type VI: anterior plagiocephaly: bilateral fronto-orbital remodelling without "bandeau".

Type VII: anterior plagiocephaly: bilateral fronto-orbital remodelling with "bandeau".

Type IX: bilateral fronto-orbital advance with expansive osteotomies.

Type X: holocranial dismantling in multiple craniosynostosis.

Type XI: posterior plagiocephaly. Occipital remodelling.

Type XII: sutural distracting techniques.

remodelling in trigonocephaly. The techniques with the highest number of complications were total cranial vault remodelling (holocranial dismantling) in scaphocephaly and multi-suture and syndromic craniosynostosis as well as distracting techniques.

Finally, mean hospitalization time in the whole series was 11.9 days (Table VII), with an ICU stay of 3 days. The highest hospitalization time corresponded to holocranial dismantling (Types IV and $\mathrm{X}$ ) and distraction techniques (Type XII).

\section{Discussion}

\section{Results}

Objective evaluation of the results in craniofacial surgery constitutes a difficult issue. Despite of the efforts made by some authors using different $\operatorname{scales}^{4,45}$, in our opinion, the end-results are still a subjective measure. On the other hand, the results of craniofacial reshaping do not parallel the difficulties that have to be met, as happens especially in multiple craniosynostosis, as are hydrocephalus, chronic raised ICP, skull base dysplasia with severe alterations in the venous drainage of the brain, tonsillar herniation sometimes associated with syringomyelic cavities, sleep apnea syndrome and chronic decrease in brain flow ${ }^{22}$. All of this features make difficult establishing a long-term prognosis in regard to intellectual capabilities, visual and auditory function and, finally, long-term survival of the more severe cases.
The global results of our patients are quite similar to those of other reported series ${ }^{29,30,41}$ consisting of $85.5 \%$ of good final results and $15.5 \%$ of poor outcomes. Craniofacial syndromes accounted for $6.36 \%$ of these poor results, $2.12 \%$ corresponded to anterior plagiocephaly and $1.76 \%$ to non-syndromic craniosynostosis. The best results corresponded to trigonocephaly (92\%) followed by scaphocephaly $(91.6 \%)$. For treatment of trigonocephaly we had to design a new frontal bone large enough to avoid narrowing of the new frontal region, which would have resulted in a poor end-result ${ }^{19,23}$. The frontal deformity in scaphocephaly ("frontal bossing") has to be treated carefully, using the appropriate techniques and taking into account the patients' age.

At present, anterior plagiocephaly represents a great challenge for the craniofacial surgeon ${ }^{2,14,20,21,29}$. We advise to use the conventional unilateral fronto-orbital advancement with "tongue-in-groove" design in the temporal region combined with supraorbital "bandeau" in severe cases and to include nasal osteotomies if neccessary. In cases of mild or moderate involvement we do not perform nasal osteotomies because the deviation of the nasal axis improves after fronto-orbital advancement.

Hydrocephalus and intracranial hypertension were frequent in our experience as is in that of others ${ }^{9,36}$. In regard to hydrocephalus, we inserted a VP shunt after the initial treatment of the synostosis. ICP monitoring was a powerful method that assisted to plan our surgical treatment, especially in cases of recurrence in multiple craniosynostosis.

In craniofacial syndromes like Crouzon's and Pfeiffer's 
and cloverleaf skull, it is important to take into account the abnormalities of the posterior skull and their physiopathological consequences. Nearly all the patients presented bone dysplasias of the posterior skull base, hydrocephalus, chronic intracranial hypertension, tonsillar herniation and even syringomyelic cavities. In these complex cases we absolutely consider surgical treatment consisting of parieto-occipital dismantling together with posterior fossa craniectomy and dural opening performed in one or two surgical stages. In our opinion, performing studies of intracranial veins, either by angio-CT scan or angio-MRI, is mandatory before planning surgical treatment to avoid severe and even lethal complications ${ }^{43}$. In our experience, posterior fossa venous abnormalities prevented a safe dural splitting in 7 of 10 cases. Nevertheless, parieto-occipital dismantling and posterior fossa craniectomy improved vault morphology and perhaps it even contributed to control hydrocephalus.

\section{Complications}

Reported mortality rates in the current literature on craniofacial surgery are very $l o w^{41}$. Fortunately, we experienced only 2 deaths in our series that occurred 1-year after the initial treatment, although the basal encephalocele of the patient with Pfeiffer's syndrome was deemed as a severe complication of our treatment. Except for this case, most complications solve favourably according to different authors ${ }^{11,13,15,41,44,45}$ and to our own experience.

The most frequent complication in our series was postoperative hyperthermia of unknown cause $(13.43 \%)$ followed by cranial infection $(7.5 \%)$. As in other publications, our infection rate was lower than $10 \%{ }^{13,15,41,44}$. Subgaleal haematomas $(5.3 \%)$, dural tears $(5 \%)$ and CSF leakage $(2.5 \%)$ occurred but in a significantly lower proportion than is reported by others ${ }^{13}$.

The remaining intracranial complications were not considered relevant, as happened with persistent cranial defects $(n=7)$, although they required repeat surgery, and with the 3 skin plate scarring.

Several issues in regard to infectious complications have been raised in previous publications as type of craniosynostosis $^{41}$, age and surgical timing ${ }^{13}$, number of surgeons, ICU stay ${ }^{48}$ and rate of reoperations ${ }^{15}$. We found two important factors related not only to infection but also to the rest of complications: a) surgical reoperations and b) type of surgical procedure.

(a). Reoperations. The rate of relapses in our series $(11.56 \%)$ was similar to that of others ${ }^{17,29}$. There is also an analogy with reports as that of Fearon et a ${ }^{15}$. The group of reoperations accounted for $62.5 \%$ of our total infection rate (7.5\%). There was even a closer correlation with the production of dural tears (5\%). 93\% of which took place at the time of reoperation. CSF leakage behaved almost the same ( $75 \%$ of the total $2.5 \%$ ). There is little doubt that adhesions in the cleavage plane, mostly in the extradural space, make surgery more difficult and may favour the occurrence of complications including that of dural tears. The use of resorbable material constitutes an issue to be taken into account that, in our view, has not been adequately addressed. As one can observe during the surgeries, resorbable materials favour the formation of adhesions in the epidural space making reoperation more difficult and increasing the risk for dural tearing.

(b). Type of surgical procedure. Type XII (fronto-orbital distraction): there has been an important number of publications in the last decade on suture distraction but they usually include few cases ${ }^{1,18,34,35}$. Something similar occurs with combined fronto-orbital and midface advancement $^{6,7,10,12,28,31,33}$ although Cruz et al's series on this regard is outstanding ${ }^{12}$. Recently, Pelo et al ${ }^{35}$ reviewed exhaustively the current literature that included 130 cases and added 8 personal instances. Complications were irrelevant and comprised local infection, device fracture and CSF leakage; although no mention to the patients' clinical condition was made in this paper.

In our series, complications were more frequent than in this last work ${ }^{35}$. There were 8 CSF leakages and 3 dural tears, as well as 8 local infections around the distracting devices in the 26 patients treated. There was only one case of device breakage. A possible explanation for our higher morbidity may lie in our indications since we used distraction as a "rescue technique" in cases of relapses or of bad results after the first operation. In fact, 9 of 26 cases had been treated previously with standard fronto-orbital advancement and most of the complications occurred in these patients (6 CSF fistula and 3 dural tears). We think that dissection of the pterional and of the anterior fossa region is not easy without elevating the frontal bones. The possibility for dural tearing is higher among reoperated patients, where multiple previous adhesions and resorbing miniplates make dissection more hazardous as has been previously reported. In one of our cases, the dural tear was made by the perforating screw of the device.

Leptomeningeal cysts $^{3}$, encephalocele ${ }^{8}$, and growing skull fracture ${ }^{47}$ have been previously described as complications of craniofacial surgery. To the best of our knowledge, our patients constitute the first report of encephalocele complicating distraction procedures, an issue that deserves especial attention. Both basal encephaloceles occurred in children with craniofacial syndromes. One of them was complicated with bilateral orbital encephalocele (Crouzon's syndrome) and the other one (Pfeiffer's syndrome) with an ethmoidal brain herniation. Both cases happened after distracting procedures combined with external devices, but both of them had been previously treated with 
standard fronto-orbital advancement at another institution. Blind osteotomies could have torn the dura mater and the distraction could have expanded the osseous gap. Both patients had undergone ICP monitoring before having been diagnosed with chronic intracranial hypertension. This factor would have probably contributed to brain herniation. The child with Pfeiffer's syndrome in our series died 18 months after encephalocele repair. Probably, death was the consequence of an incomplete isolation of the skull base during our treatment.

Type I procedure, corresponding to endoscopically assisted osteotomies in scaphocephaly was the technique with fewer complications. Types II (standard procedure for scaphocephaly) and III (II plus frontal remodelling) complication rates were not significantly higher. However, in patients submitted to holocranial dismantling, such as scaphocephaly (type IV) and multiple craniosynostosis (type XI) complications were much commoner.

The treatment for trigonocephaly is presently well established $^{19,29}$ and in our experience fronto-orbital remodelling without fronto-orbital bandeau (type $\mathrm{V}$ ) has proved to be an effective technique with a low morbidity rate $^{23}$. On the contrary, anterior plagiocephaly has always been more laborious to correct, being complications more frequent and its results difficult to predict ${ }^{2,14,20,21,39}$. Nevertheless, there were few complications among our patients and we did not find significant differences between the two techniques performed (Type VII: frontal bilateral remodelling without frontal-orbital "bandeau" and Type VIII: frontal bilateral remodelling with frontal-orbital "bandeau"). Finally, type IX technique (standard bilateral fronto-orbital advancement with expanding osteotomies in multiple craniosynostosis) had a low rate of complications, moreover taking into account that it was used frequently for relapses (8 of 30 cases).

Accordingly, the procedure with the lowest rate of complications was type I (endoscopically assisted osteotomies) followed by standard frontal-orbital advancement (type IX) and surgical procedures for trigonocephaly (type V) and anterior plagiocephaly (types VI and VII). On the contrary, types XII (fronto-orbital distraction) and holocranial dismantling (types IV and X) originated the highest number of complications.

Postoperative non-infectious hyperthermia without a causal explanation occurs frequently in craniofacial surgery $^{11,42}$. It was also the most frequent complication in our series $(13.43 \%)$ but it usually happened in certain procedures: type II, sagittal suturectomy and expansive osteotomies plus frontal dismantling in scaphocephaly, and types IV and $\mathrm{X}$ (holocranial dismantling procedures) suggesting that there exists a relationship between larger tissue exposures and, probably, a higher rate of blood transfusions. Finally, we think that 11.9 days as a mean hospitalization time in our patients is unacceptable, but this was attributed to administrative procedures that escape our competences. It is of note that longer periods of hospital stay are related to a higher rate of complications (Table VII).

\section{Management considerations}

Regarding to our results and complication rates and also to patients' age at surgery; we suggest the following considerations for craniosynostosis management.

\section{Scaphocephaly}

We think that the technique of election for scaphocephaly for most cases under age 4-months should be endoscopically assisted suturectomy and osteotomies with postoperative orthosis. In older children we use open suturectomy and expanding osteotomies, and frontal osteotomies, remodelling or parietal transposition in cases with severe frontal bossing. Holocranial dismantling through expanding osteotomies and fronto-orbital remodelling of the frontal bossing should be reserved for patients over age 1-year.

\section{Trigonocephaly}

Our previously reported technique yielded very good results. The patient's age at operation should not be lower than 5-6 months as the deformity may improve spontaneously in younger patients.

\section{Anterior plagiocephaly}

In our opinion, there is not a major difference in terms of complications between using or not using the tonguein-groove fronto-orbital "bandeau". We reserve the "bandeau" with nasal osteotomies for the most severe cases with vertical dystopia. As in trigonocephaly, the age at surgery should not be lower than 5-6 months.

\section{Multiple craniosynostosis}

Standard bilateral fronto-orbital advancement continues to be the technique of choice for treatment of most cases with brachycephaly and turricephaly and has fewer complications than distracting procedures. On the other hand, total cranial vault remodelling (holocranial dismantling) has a high incidence of complications and therefore should be reserved for those cases where the vault and the skull base are severely distorted. We must consider solving these cases under staged procedures.

Use of distracting devices at onset is questionable probably due to the fact that they had been a recent acquisition in our surgical armamentarium. Nevertheless, we think that after having treated 26 cases we are prepared to settle some preliminary conclusions. We do not think that distraction is an election technique in anterior plagiocephaly as conventional techniques offer better results and fewer compli- 
cations. These techniques could be used in the less severe cases.

We think that standard fronto-orbital advancement in multiple craniosynostosis provides the best results with fewer complications although distracting techniques may play a role in less severe cases of brachycephaly, as a "rescue surgery" after relapsing multiple craniosynostosis and in some craniofacial syndromes with extensive preoperatory bone defects. To end with, we think that combined fronto-orbital and midface distraction, as happened in the past with monobloc advancement, may involve serious complications and so it should be reserved for special cases as are toddlers with severe exophthalmia and harsh respiratory obstruction.

Finally, in those cases with major alterations in the posterior region of the skull and in the posterior fossa, the recommended treatment would be to start with a complete parieto-occipital dismantling with posterior craniectomy and dural opening if possible. The ideal age for surgery should be close to 6-month excepting for real emergencies such as are cases with severe intracranial hypertension, gross hydrocephalus, important exophtalmus and severe sleep-apnea syndrome.

\section{Conclusions}

a. Our mortality rate was 2 of 283 cases. The 2 deaths occurred 1-year after surgery.

b. $85.5 \%$ of our patients obtained a good end-result in regard to craniofacial shape while $15.5 \%$ showed a poor result. These unsatisfactory results occurred in children with craniofacial syndromes $(6.36 \%)$, anterior plagiocephaly $(2.12 \%)$ or multiple craniosynostosis $(1.76 \%)$.

c. In relation to clinical groups, the worst results corresponded to craniofacial syndromes $(58 \%$ in categories III and IV) followed by non-syndromic multiple craniosynostosis $(25 \%)$ and anterior plagiocephaly $(21.4 \%)$.

d. We noted the best results in trigonocephaly (92\%) followed by scaphocephaly $(91.6 \%)$.

e. The most frequent complication was postoperative hyperthermia (13.43\%), followed by infection $(7.5 \%)$, subgaleal haematoma $(5.3 \%)$, dural tears (5\%) and CSF leakage (2.5\%).

f. There was a significant correlation between complications and reoperations $(11.56 \%)$. For instance, $62.5 \%$ of infections, $93 \%$ of dural tears and $75 \%$ of CSF leakages belong to the group of reoperated patients.

g. Complications changed also according to the type of surgical procedure. The types of procedure with the lowest number of complications were endoscopy- assisted suturectomy followed by standard frontoorbital advancement, fronto-orbital remodelling in trigonocephaly and fronto-orbital remodelling in anterior plagiocephaly. The techniques with the highest rate of complications were distraction techniques followed by total cranial vault remodelling (holocranial dismantling) in scaphocephaly and multiple and syndromic craniosynostosis.

h. Postoperative hyperthermia of undetermined nature and mean hospitalization time followed the above mentioned tendency and increased in the same procedures.

i. Finally, according to our experience, we have established considerations on the outcomes relating them to each specific technique, age at surgery, complications and the results of the series.

\section{Bibliography}

1. Akai, T., Iizuka, H., Kawakam, S.: Treatment of craniosynostosis by distraction osteogenesis. Pediatr Neurosurg 2006; 42: 288-292.

2. Anderson, P. J., David, D.J.: Late results after unicoronal craniosynostosis correction. J Craniofac Surg 2005; 16: 37-44.

3. Aryan, H.E., Meltzer, H.S., Gerras, G.G., Jandial, R., Levy, M.L.: Leptomeningeal cyst development after endoscopic craniosynostosis repair: case report. Neurosurgery 2004; 55: 235-237.

4. Barlett, S.P., Whitaker, L.A., Marchac, D.: The operative treatment of isolated craniofacial dysostosis (plagiocephaly): A comparison of the unilateral and bilateral techniques. Plast Reconstr Surg 1990; 85: 677.

5. Barone, C.M., Jimenez, D.F.: Endoscopic approach to coronal craniosynostosis. Clin Plast Surg; 2004; 31: 415-422.

6. Blount, J.P., Louis Jr, R.G., Tubbs, R.S., Grant, J.H.: Pansynostosis: a review. Child's Nerv Syst 2007; 23: 11031109.

7. Bradley, J.P., Gabbay, J.S, Taub, P.J, Heller, J.B., O'Hara, C.M., Benhaim, P., Kawamoto, H.K Jr.: Monobloc advancement by distraction osteogenesis decreases morbidity and relapse. Plast Reconstr Surg 2006; 118: 1585-1597.

8. Caplan, J., Ange, M., Parent, A.: Encephalocele as a late complication of cranial vault reconstruction in a patient with Crouzon's syndrome. J Craniofac Surg 2002; 13: 501-504.

9. Cinalli, G., Sainte-Rose, C., Kollar, E.M., Zerah, M., Brunelle, F., Chumas, P., Arnaud, E., Marchac, D., PierreKahn, A.: Hydrocephalus and craniosynostosis. J Neurosurg 1998; 88: 209-214.

10. Cohen, S.R., Boydston, W., Hudgins, R., Burstein, F.D.: Monobloc and facial bipartition distraction with internal devices. J Craniofac Surg 1999; 10: 244-251.

11. Craig, H. P., Masson, J, A., Herrera, R., Ginsburg, 
C.M., Sklar, F., Sinn, D.P., Syrd, H.S.: Fever after Craniofacial surgery in the infant under 24 months of age. Plast Reconstr Surg 1998; 102: 32-36.

12. Cruz, A.A., Akaishi, P.M., Arnaud, E., Marchac, D., Renier, D.: Exorbitism correction of faciocraniosynostosis by monobloc frontofacial advancement with distraction osteogenesis. J Craniofac Surg 2007; 18: 355-360.

13. David, J.D., Cooter, R.D.: Craniofacial infection in 10 years of transcranial surgery Plast and Reconstr Surg 1987; 80: 213-225.

14. Esparza, J., Muñoz, M. J., Hinojosa, J., Romance, A., Muñoz, A., Méndez, M.D.: Operative treatment of the anterior synostotic plagiocephaly: analysis of 45 cases. Child's Nerv Syst 1998; 14: 448-454.

15. Fearon, J.A., Bartlett, S.P., Munro, I.R., Whitaker, L.: Infections in craniofacial surgery: a combined report of 567 procedures from two centers. Plast Reconstr Surg 1997; 100 : 862-868.

16. Ferreira, M.P., Collares, M.V., Ferreira, N.P., Kraemer, J.L., Pereira Filho, A. de A., Pereira Filho G. de A.: Early surgical treatment of nonsyndromic craniosynostosis. Surg Neurol 2006; 65 Suppl 1: S1: 22-1: 26.

17. Forster, K.A., Frim, D.M., McKinnon, M.: Recurrence of synostosis following surgical repair of craniosynostosis. Plast Reconstr Surg 2008, 121: 70-76.

18. Fujimori, Y., Ueda, K., Oba, S.: Additional distraction osteogenesis after conventional fronto-orbital advancement. J Craniofac Surg 2005; 16: 1064-1069.

19. Greenberg, B.M., Schneider, S.J.: Trigonocephaly: surgical considerations and long term evaluation. J Craniofac Surg 2006; 17: 528-535.

20. Guouo, Z., Ding, M., Mu, X., Chen, R.: Operative treatment of coronal craniosynostosis: 20 years of experience. Surg Neurol 2007; 68 (6 Suppl): S18-21.

21. Hansen, M., Padwa, B.L., Scout, R.M., Stieg P.E., Mulliken J.B.: Synostotic frontal plagiocephaly: anthropometric comparison of three techniques for surgical correction. Plast Reconstr Surg 1997; 100: 1387-1395.

22. Hayward, R., Gonzalez, S.: How low can you go? Intracranial pressure, cerebral perfusion pressure, and respiratory obstruction in children with complex craniosynostosis. J Neurosurg (Pediatrics), 2005; 102: 16-22.

23. Hinojosa, J., Esparza, J., Muñoz, M.J., Salván, R., Romance, A., Alén, J.F., Muñoz, A.: Surgical treatment of trigonocephalies and associated hypoteleorbitism. Neurocirugía, 2002; 13: 437-445.

24. Hinojosa, J., Esparza, J., Muñoz, M,J.: Endoscopicassisted osteotomies for the treatment of craniosynostosis. Child's Nervous Syst 2007; 23: 1421-1430.

25. Israele, V., Siegel, J.D.: Infectious complications of craniofacial surgery in children. Rev Infec Dis 1989; 11: 915.

26. Jiménez, D.F., Barone, C.M., McGee, M.E, Cart- wright, C.C., Baker, C.L.: Endoscopy-assisted wide-vertex craniectomy, barrel stave osteotomies, and postoperative helmet molding therapy in the management of sagittal suture craniosynostosis. J Neurosurg 2004; 100 (5 Suppl Pediatrics): 407-417.

27. Jiménez, D.F, Barone, C.M.: Early treatment of anterior calvarial craniosynostosis using endoscopic-assisted minimally invasive techniques. Child's Nerv Syst. 2007 23: 1411-1419.

28. Kubler, A.C., Speder, B., Zoller, J.E.: Fronto-orbital advancement with simultaneous Le Fort III-distraction. J Craniomaxillofac Surg 2004; 32: 291-295.

29. McCarthy, J.G., Glasberg, S.B, Cutting, B., Epstein, F.J., Gravson, B.H., Ruff, G., Thorne, C.H., Wisoff, J., Zide, B.M.: Twenty-year experience with early surgery for craniosynostosis: I. Isolated craniofacial synostosis -results and unsolved problems. Plast Reconstr Surg 1995; 96: 272-283.

30. McCarthy, J.G., Glasberg, S.B., Cutting, B., Epstein, F.J., Gravson, B.H., Ruff, G., Thorne, C.H., Wisoff, J., Zide, BM.: Twenty-year experience with early surgery for craniosynostosis: II. The craniofacial synostosis syndromes and pansynostosis- results and unsolved problems. Plast Reconstr Surg 1995, 96: 284-295.

31. Meling, A.C., Due-Tonnessen, B.J., Hogevold, H.E., Skelbred, P., Arctander, K.: . .Monobloc distraction osteogenesis in pediatric patients with severe syndromal craniosynostosis. J Craniofac Surg 2004; 15: 990-1000.

32. Muñoz, M.J., Esparza, J., Hinojosa, J., Salván, R., Romance, A., Muñoz, A.: Fronto-orbital remodelling without orbito-naso-frontal bandeau. Child's Nerv Syst 2003; 19: 353358 .

33. Nadal, E., Doghliotti, P.L., Rodríguez, J.C., Zuccaro, G.: Craniofacial distraction osteogenesis en bloc. J Craniofac Surg 2000; 11: 246-51.

34. Nishimoto, S., Oyama, T., Nagashima, T., Shimizu, F., Tsugawa, T., Takeda, M., Toda, N.: Distraction fronto-orbital advancement with 'floating forehead' for patients with syndromic craniosynostosis. J Craniofac Surg 2006; 17: 497-505.

35. Pelo, S., Gasparini, G., Di Petrillo, A., Tamburini, G., Di Rocco, C.: Distraction osteogenesis in the surgical treatment of craniostenosis: a comparison of internal and external craniofacial distractor devices Child's Nerv Syst 2007; 23: 1447-1453.

36. Renier, D., Sainte-Rose C., Marchac, D., Hirsch, J.F.: Intracranial pressure in craniostenosis. J Neurosurg 1982; 57 : 370-377.

37. Renier, D., Lajeunie, E., Arnaud, E., Marchac, D.: Management of craniosynostosis. Child's Nerv Syst 2000; 16: 645-658.

38. Resnick, D.K., Pollak, I.F., Albright, A.L.: Surgical management of the cloverleaf skull deformity. Pediatric Neurosurgery $1995 ; 22:$ 29-37.

39. Selber, J.C., Brooks, C., Kurichi, J.E., Temmen, T., 
Sonnad, S.S., Whitaker, L.A.: Long-term results following fronto-orbital reconstruction in nonsyndromical unicoronal synostosis. Plast Reconstr Surg 2008; 121: 251-260.

40. Sgouros, S., Goldin, J.H., Hockley, A.D., Wake, M.J.: Posterior skull surgery in craniosynostosis. Child's Nerv Syst. 1996; 12: 727-733.

41. Sloan, G.M., Wells, K.C., Raffel, C., McComb, J.G.: Surgical treatment of craniosynostosis: outcome analysis of 250 consecutive patients. Pediatrics 1997; 100 (1): E2.

42. Takagi, S., Anderson, P.J., David, D.J.: Pyrexia after transcranial surgery. J Craniofac Surg 2006; 17: 202-204.

43. Thompson, D.P., Hayward, R.D., Harkness, W.J., Jones, B.J.: Lessons from a case of kleeblattschädel. J Neurosurg 1995; 82: 1071-1074.

44. Whitaker, L. A, Munro, I. R., Salyer, K. E., Jackson, I.T., Ortiz-Monasterio, F., Marchac, D.: Combined report of problems and complications in 793 craniofacial operations. Plast Reconstr Surg 1979; 64: 198-203.

45. Whitaker, L.A, Bartlett, S.P., Schut, L., Bruce, D.: Craniosynostosis: An analysis of the timing, treatment and complications in 164 consecutive patients. Plast Reconstr Surg 1987; 80: 195-212.
46. Wong, G.B., Kakulis, E.G., Mulliken, J.B.: Analysis of fronto-orbital advancement for Apert, Crouzon, Pfeiffer and Saethre-Chotzen syndromes. Plast Reconstr Surg 2000; 105: 2314-2323.

47. Yamamoto, M., Moore, M.H., Hanieh, A.: Growing skull fracture after cranial vault reshaping in infancy. J Craniofac Surg 1998; 9: 73-75.

48. Yeung, L.C., Cunningahm, M.L., Allpress, A.L., Gruss, J.S., Ellenbogen, R.G., Zerr, D.M.: Surgical site infections after pediatric intracranial surgery for craniofacial malformations: frequency and risk factors. Neurosurgery 2005; 56: 733-739.

Esparza, J.; Hinojosa, J.; García-Recuero, I.; Romance, A.; Pascual, B.; Martínez de Aragón, A.: Surgical treatment of isolated and syndromic craniosynostosis. Results and complications in 283 consecutive cases. Neurocirugía 2008; 19 : 509-529.

Corresponding author's address: Dr. Javier Esparza. Servicio de Neurocirugía Pediátrica. Hospital Infantil 12 de Octubre. Avda de Córdoba s/n. 28041 Madrid. 